\title{
Cervical corpectomy for sub-axial retro-vertebral body lesions
}

\author{
Mohamed A. Eshra(i)
}

\begin{abstract}
Background: The sub-axial vertebrae are formed of body, pedicles, laminae, facets, and spinous process. Cervical cord compression by anteriorly located retro-vertebral traumatic, inflammatory, neoplastic, and degenerative lesions is not rare, and in such cases, simple discectomy does not solve the problem. Corpectomy, grafting, and plating may help in management of these dangerous lesions.

Methods: From May 2014 to December 2016, 30 cases with cervical myelopathy due to anteriorly located retro-vertebral traumatic, inflammatory, neoplastic, and degenerative lesions were operated upon by single, double, or triple levels corpectomy, grafting by bone graft or corpectomy cage and plating. Patients were followed up for 1 to 3 years both clinically and radiologically.
\end{abstract}

Results: Improvement of myelopathic manifestations (partial or complete) occurred in all cases within a variable time from 3 to 15 months. Bony fusion was sound in 27 cases and poor in 3 cases. Post-operative complications were mild and reversible.

Conclusions: Corpectomy, grafting, and plating give a very good decompressive chance to the compressed cord by retro-vertebral lesions without any added risk.

Keywords: The sub-axial vertebrae, Myelopathy, Corpectomy

\section{Background}

The sub-axial vertebrae are formed of body, pedicles, laminae, facets, and spinous process. The spinal cord surrounded by its meninges is located in the spinal canal formed by the posterior aspect of vertebral bodies, two pedicles, and two laminae. Any lesion which may lead to narrowing of the spinal canal would result in spinal cord compression [1-3].

Cervical cord compression by anteriorly located retrovertebral traumatic, inflammatory, neoplastic, and degenerative lesions is not rare, and in such cases, simple discectomy does not solve the problem. Corpectomy, grafting, and plating would be considered as the ideal management of these dangerous lesions. The corpectomy provides adequate decompression of the cord. Bone grafting maintains the vertebral height and provides adequate vertebral orientation and stability. Plating prevents graft dislodgment and increases the rate of bony fusion [4-9].

Correspondence: alatoolneuro@gmail.com

Department of Neurosurgery, Faculty of Medicine, Alexandria University, Champillion St., Elazaritta, Alexandria, Egypt
In this study, we tried to investigate the safety and efficacy of doing such corpectomy in patients who had spinal cord compression by retro-vertebral body lesions.

\section{Methods}

This is a retrospective study conducted from May 2014 to December 2016; 30 cases with cervical myelopathy due to anteriorly located retro-vertebral lesions were operated upon. These lesions were traumatic in 12 patients, inflammatory in 5 patients, neoplastic in 7 patients, and degenerative in 6 patients. All patients were assessed by both clinical and radiological methods. A left-sided transverse incision was used in single-level procedures whereas a longitudinal incision was used in double- or triple-level corpectomy. All traumatic lesions were operated upon by single-level corpectomy. Four inflammatory lesions were operated upon by single level whereas one patient was operated upon by double-level corpectomy. Five patients with neoplastic lesions were operated upon by single level whereas 2 patients were 


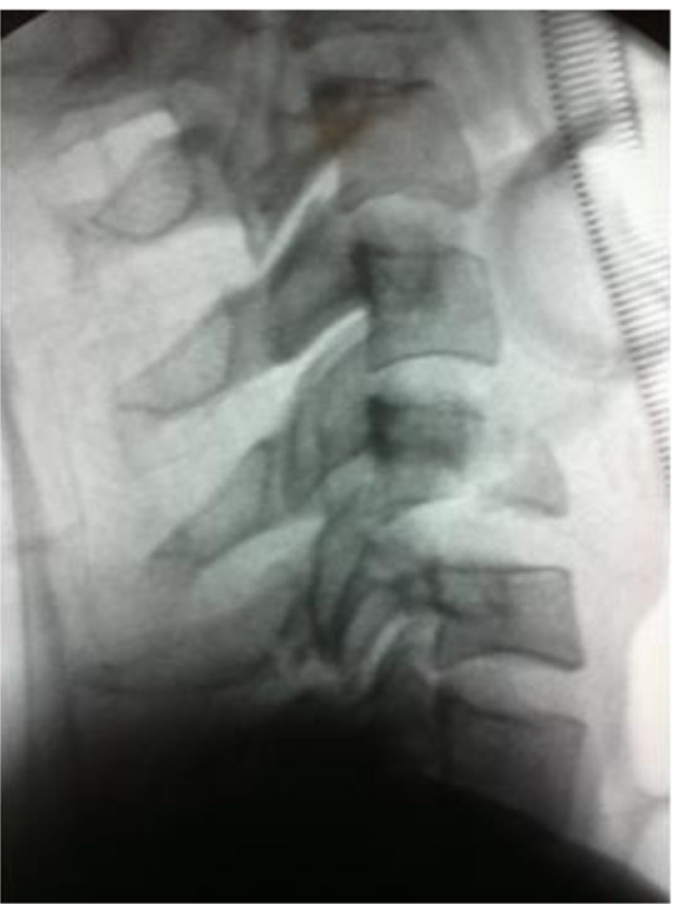

Fig. 1 Plain X-ray (intra-operative fluoroscopy) showing C5 fracture with retrolisthesis of $C 5$

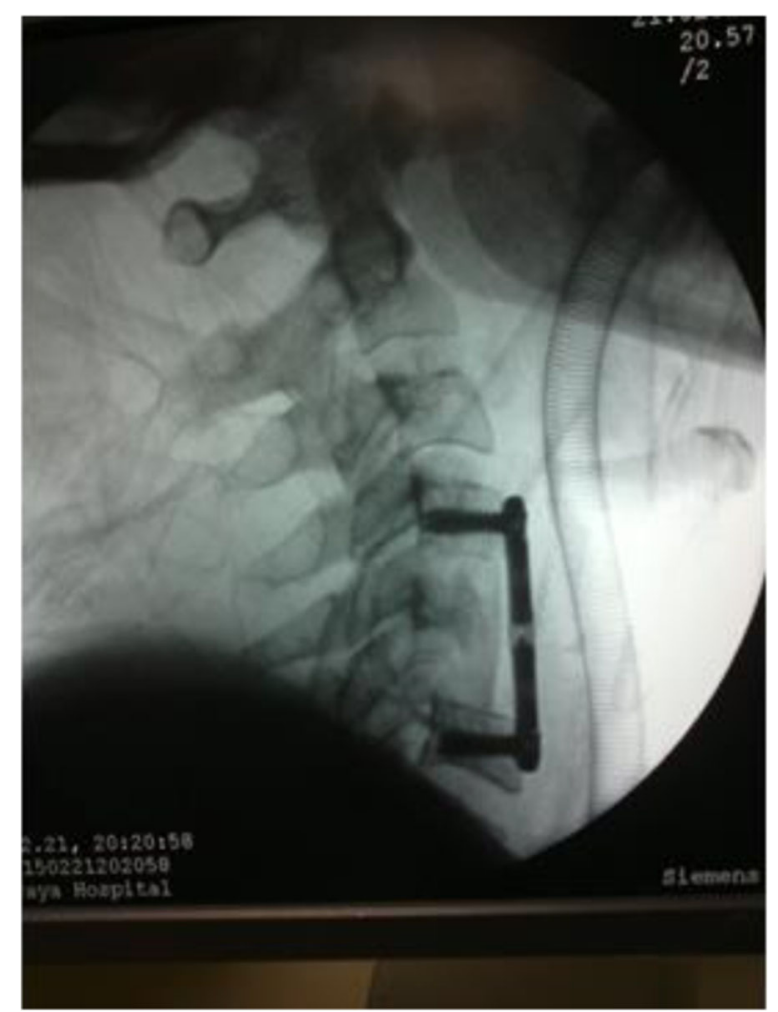

Fig. 2 Fluoroscopic image showing corpectomy of C5, iliac crest bone grafting, and C4-C6 plating

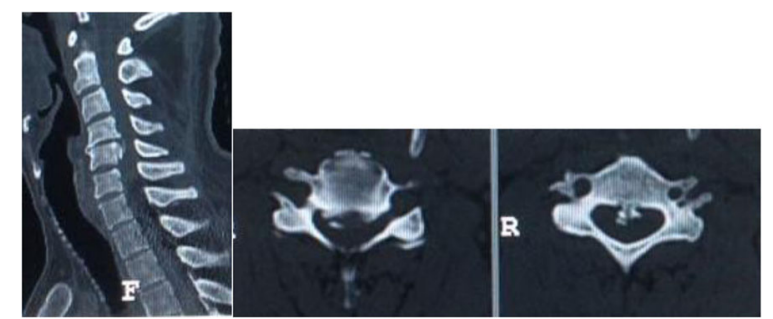

Fig. 3 CT of cervical spine showing focal stenosis due to $C 5$ retro-vertebral ossification

operated upon by double-level corpectomy. Two patients with degenerative lesion were operated upon by single level, three patients were operated upon by double level, and one patient was operated upon by triple-level corpectomy. After the exposure of the anterior aspect of the cervical bodies and detection of the affected level with the guide of fluoroscopy, the upper and lower anterior discectomies were done (Fig. 1). With the use of micro-curettes

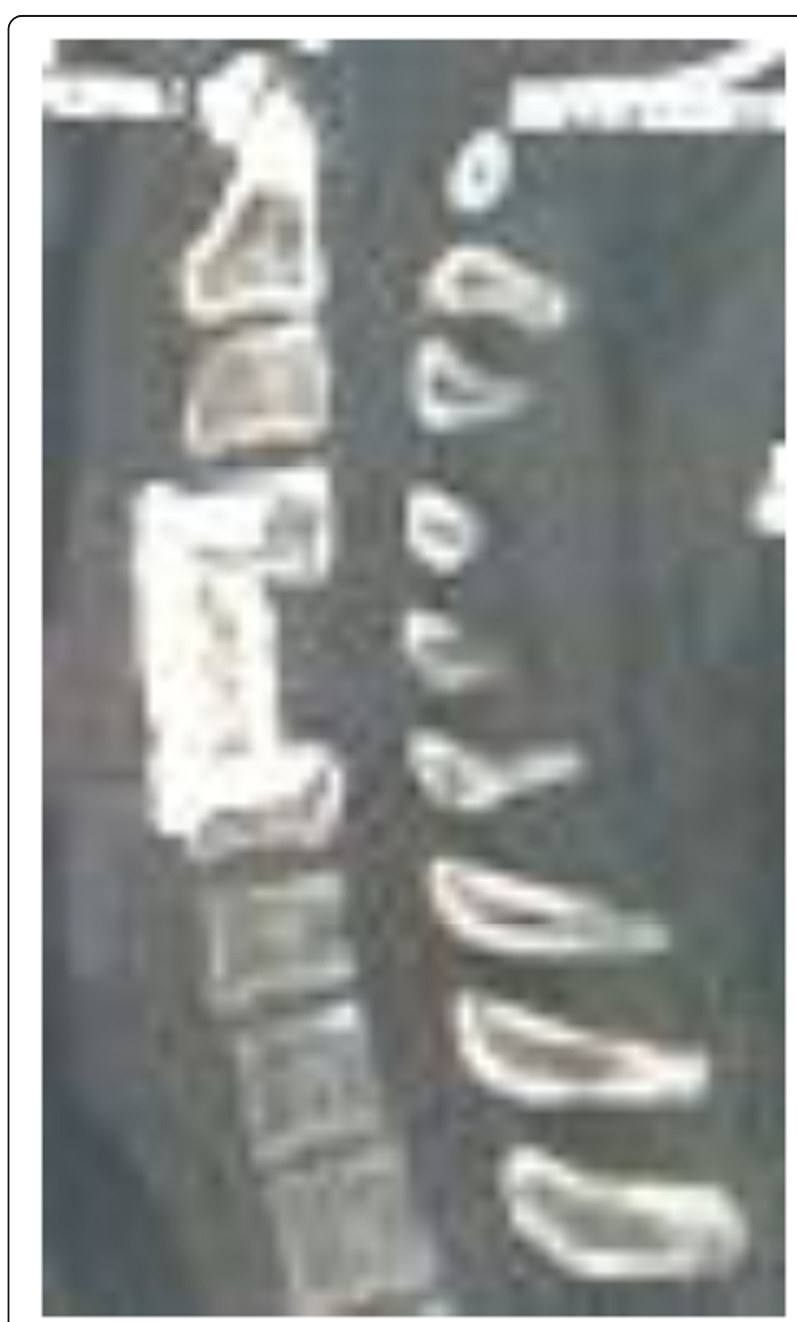

Fig. 4 C5 corpectomy, mesh graft, and C4-C6 plating 
and high-speed drill, the affected body was removed till reaching the posterior cortex of the body which was removed by the diamond piece exposing the posterior longitudinal ligament which was also removed to expose compressed anterior dura and ensure complete removal of the pressure on the spinal cord. Grafting by iliac crest bone graft only was done in 3 cases with single corpectomy whereas corpectomy cages or mesh grafts filled by autologous bone fragment were used in 27 cases (Figs. 2, 3, and 4). Plating was performed in all patients with fluoroscopic guidance. Hard neck collar was advised for all patients. Plain radiography was done $6 \mathrm{~h}$ post-operatively to check the alignment of the graft and plate, inter- vertebral height, and spinal curvature. Patients stayed in the hospital for 1-3 days. No patient needed postoperative ICU admission. Patients were followed up for 1 to 3 years both clinically and radiologically.

Neck Disability Index (NDI) $[10,11]$ which is a modification of Oswestry Disability Index (ODI) was used to evaluate all patients, pre- and post-operatively. The ODI was scored on a scale from 0 to 100 using the Oswestry Disability Questionnaire of 10 items (personal care, lifting objects, sitting, standing, walking, sleeping, sex life, social life, traveling, and need for medications). The higher the index means more disability. If the pre-operative index is decreased post-operatively, this means that the patient is

Table 1 Summary of clinical data

\begin{tabular}{|c|c|c|c|c|c|c|c|c|}
\hline No. & Age/sex & Lesion & Level (s) & Graft & $\begin{array}{l}\text { Operative } \\
\text { time (min) }\end{array}$ & $\begin{array}{l}\text { Pre-operative } \\
\text { motor power }\end{array}$ & $\begin{array}{l}\text { Post-operative } \\
\text { motor power } \\
\text { (1 month) }\end{array}$ & $\begin{array}{l}\text { Post-operative } \\
\text { complications }\end{array}$ \\
\hline 1 & $23 / M$ & Traumatic & Single & Cage & 105 & 2 & 4 & Dysphagia \\
\hline 2 & $41 / M$ & Traumatic & Single & Mesh & 94 & 4 & 5 & \\
\hline 3 & $35 / M$ & Traumatic & Single & Iliac crest & 120 & 4 & 5 & \\
\hline 4 & $31 / F$ & Traumatic & Single & Cage & 90 & 1 & 4 & Dysphagia \\
\hline 5 & $55 / M$ & Traumatic & Single & Iliac crest & 110 & 3 & 5 & \\
\hline 6 & 29/M & Traumatic & Single & Cage & 120 & 4 & 5 & Dysphagia \\
\hline 7 & $34 / M$ & Traumatic & Single & Cage & 99 & 4 & 5 & \\
\hline 8 & $24 / M$ & Traumatic & Single & Mesh & 115 & 4 & 5 & \\
\hline 9 & $47 / F$ & Traumatic & Single & Mesh & 98 & 3 & 4 & \\
\hline 10 & $33 / M$ & Traumatic & Single & Mesh & 94 & 4 & 5 & \\
\hline 11 & $51 / \mathrm{M}$ & Traumatic & Single & Cage & 90 & 2 & 4 & \\
\hline 12 & $34 / M$ & Traumatic & Single & Iliac crest & 110 & 3 & 4 & Dysphagia \\
\hline 13 & $44 / M$ & Inflammatory & Single & Mesh & 90 & 4 & 5 & Fever \\
\hline 14 & $38 / M$ & Inflammatory & Single & Cage & 93 & 5 & 5 & \\
\hline 15 & $27 / M$ & Inflammatory & Single & Mesh & 99 & 3 & 5 & \\
\hline 16 & $47 / F$ & Inflammatory & Double & Mesh & 120 & 4 & 5 & \\
\hline 17 & $32 / F$ & Inflammatory & Single & Cage & 100 & 4 & 5 & Fever \\
\hline 18 & $55 / M$ & Neoplastic & Single & Mesh & 90 & 4 & 5 & \\
\hline 19 & $46 / M$ & Neoplastic & Single & Mesh & 95 & 5 & 5 & \\
\hline 20 & $60 / F$ & Neoplastic & Double & Mesh & 110 & 4 & 5 & \\
\hline 21 & $67 / M$ & Neoplastic & Single & Mesh & 90 & 4 & 5 & \\
\hline 22 & $44 / M$ & Neoplastic & Single & Cage & 120 & 5 & 5 & \\
\hline 23 & $77 / M$ & Neoplastic & Single & Mesh & 96 & 3 & 5 & \\
\hline 24 & $51 / F$ & Neoplastic & Double & Mesh & 100 & 4 & 5 & Numbness \\
\hline 25 & $66 / F$ & Degenerative & Triple & Mesh & 150 & 4 & 5 & \\
\hline 26 & $58 / F$ & Degenerative & Single & Cage & 100 & 4 & 5 & \\
\hline 27 & $61 / M$ & Degenerative & Single & Mesh & 95 & 3 & 4 & \\
\hline 28 & $67 / M$ & Degenerative & Double & Mesh & 120 & 4 & 5 & \\
\hline 29 & $79 / M$ & Degenerative & Double & Mesh & 105 & 5 & 5 & \\
\hline 30 & $55 / M$ & Degenerative & Double & Mesh & 130 & 4 & 5 & \\
\hline
\end{tabular}


improved and vice versa. This index can indirectly measure the motor functions of patients, but we also measured the motor power on the slandered motor power scale from 0 to 5 for all patients pre- and post-operatively.

Summary of the clinical data of the cases is demonstrated in Table 1.

\section{Results}

The operative time was between 90 and $150 \mathrm{~min}$. Blood loss was from 300 to $750 \mathrm{~cm}^{3}$. Post-operative complications, occurred in 7 patients, were minor and transient in the form of fever, dysphagia, and numbness along the upper limbs.

One month post-operatively, the motor power grading was increased and NDI decreased in all patients as compared with the records obtained pre-operatively.

The clinical outcome was Excellent $(\mathrm{NDI}=0-20)$ in 23 patients, Very good (NDI $=21-40)$ in 2 patients, and Good (NDI $=41-60)$ in 4 patients, and Fair outcome (NDI $=61-80)$ was encountered in 1 patient. No Poor outcome (NDI $=81-100)$ was faced in any patient. After 1 year of follow-up, bony fusion was sound in 27 cases and poor in 3 cases. These 3 cases were subjected to revision surgery where the cage grafts were replaced by mesh grafts with refreshment of the upper and lower end plates and revision plate and screws were used. These 3 cases were subjected to follow-up for 5 months only and the success of fusion was not documented and the follow-up is going on.

\section{Discussion}

In the present study, the pathologies compressing the cord were anterior to the cord and located posterior to the vertebral bodies, so simple anterior discectomy could not resolve the problem and corpectomy was mandatory to decompress the anterior aspect of the cord. No neurological injury or added complications were observed to be related to sub-total removal of the vertebral bodies except acceptable increase in blood loss, and this is matching with the results reported [12].

Bone grafting is mandatory to reconstruct the anterior column to minimize the stress on the plates and screws and should be inserted under distraction to maintain the vertebral height, widen the foramina, and apply compressive force on the graft which enhances bony fusion. Excessive distraction was avoided for fear of neural injury [13]. Two types of grafts were used, allografts from iliac crest and synthetic grafts in the form of cages or meshes. No differences between the two types of grafts were observed except the donor site pain in allografts.

Some authors preferred to do posterior stabilization in addition to the anterior one especially in multi-level corpectomy; however, in this study, this approach was not

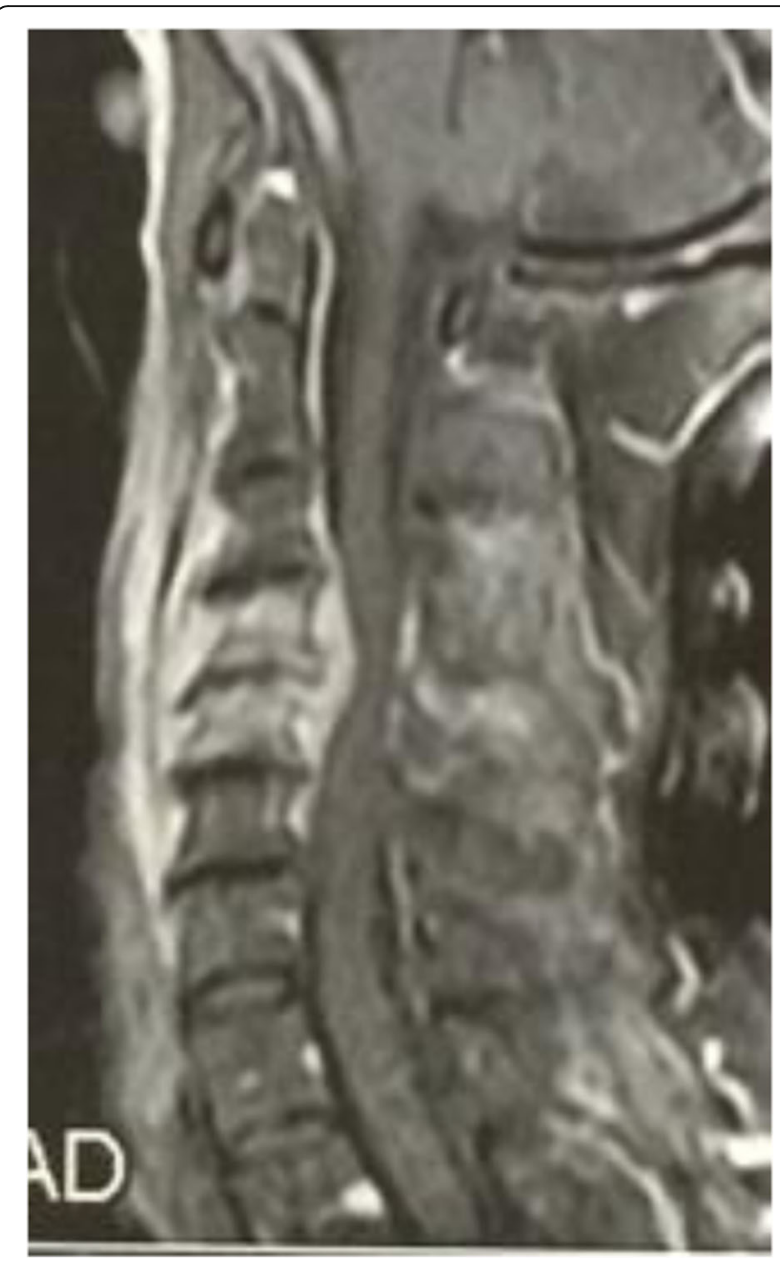

Fig. $5 \mathrm{MRI}$ of cervical spine showing infective soft tissue mass opposite C4 and C5

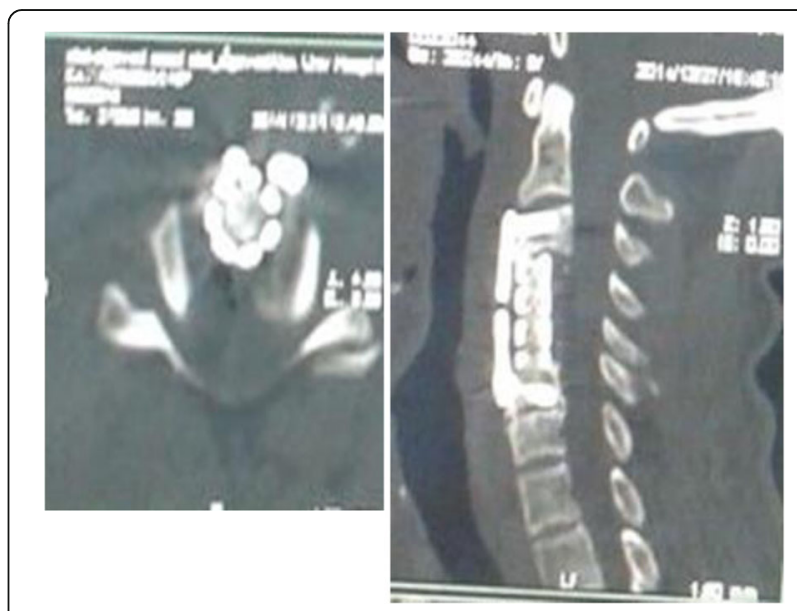

Fig. 6 CT of cervical spine showing C4 and C5 corpectomy, mesh graft, and plating of $\mathrm{C} 3$ and $\mathrm{C} 6$ 
applied even in multi-level diseases and the follow-up of the patients proved that the anterior approach alone is sufficient to achieve a sound fusion and maintained cervical lordosis [14] (Figs. 5, 6, 7, and 8).

Few authors preferred not to do plating in the presence of infected collection to avoid flourishing of infection, but in this study, the infection started to subside gradually after the operation as drainage of the collection done by corpectomy diminished the bacterial inoculum and quickened the healing [15].

Degeneration of the upper or lower levels adjacent to the fused segment was reported by some authors. This was not the case during the follow-up period of the current study $[16,17]$.

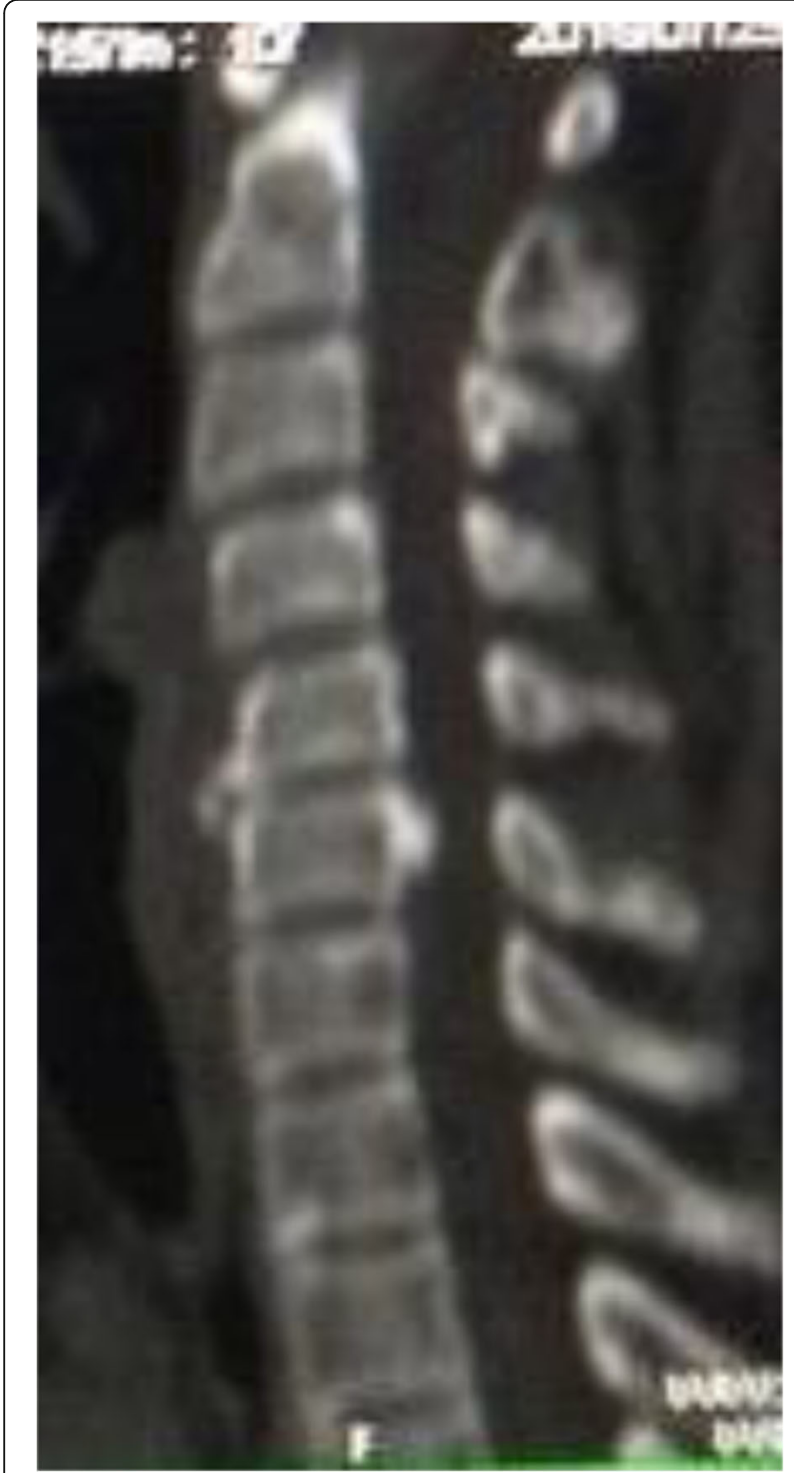

Fig. $7 \mathrm{CT}$ of cervical spine showing focal stenosis due to C6 retro-vertebral ossification

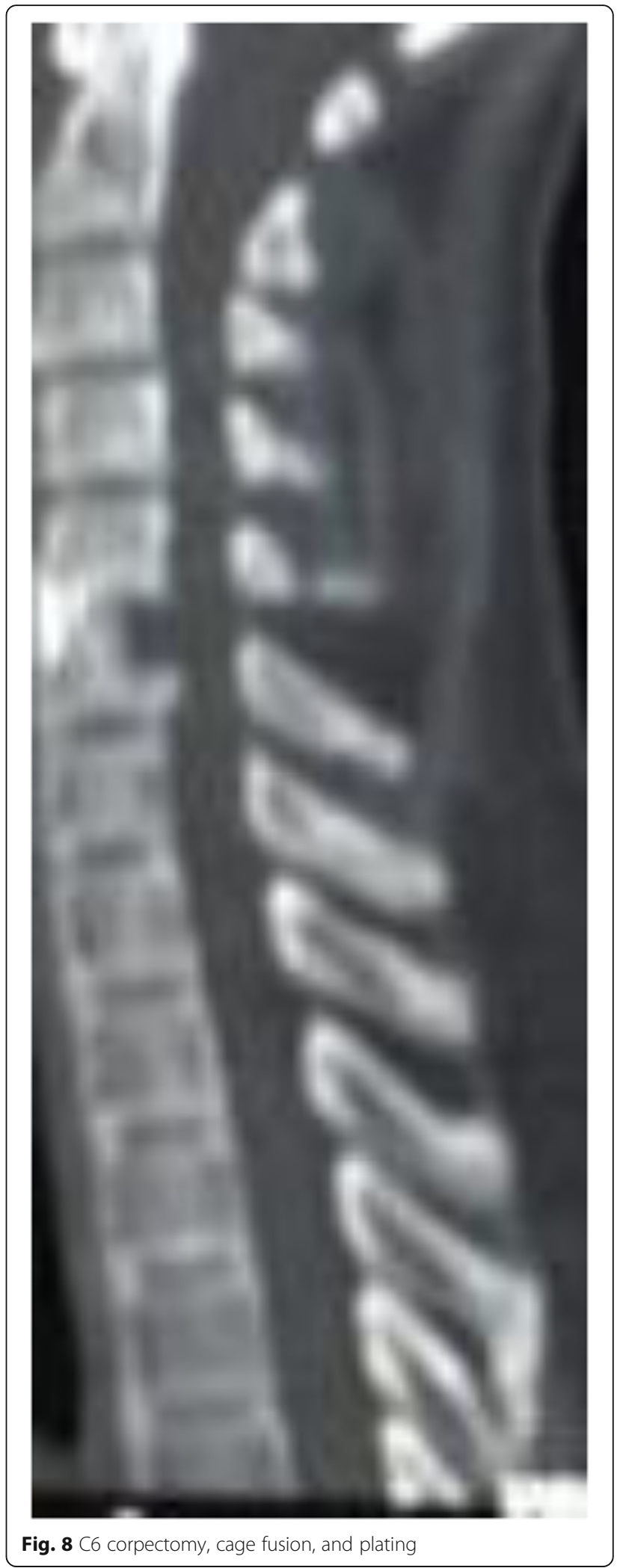

Fig. 8 C6 corpectomy, cage fusion, and plating 
Kato et al. concluded that cervical corpectomy is the treatment of choice in treating acquired cervical canal stenosis whether focal or diffuse. The corpectomy is followed by grafting to reconstruct the anterior column and plating to support the spine and act as a tension band to facilitate the bony fusion. Moreover, corpectomy and grafting have the potential to allow reduction of kyphotic deformities that exacerbate cervical myelopathy as they restore the cervical physiological curvature [18].

\section{Conclusions}

Corpectomy gives a very good decompressive chance to the compressed cord by retro-vertebral lesions without any added risks. Grafting and plating are essential to reconstruct and stabilize the cervical spine.

\section{Funding}

The author received no specific funding for this work.

\section{Availability of data and materials}

Data sharing is not applicable to this article as no datasets were generated or analyzed during the current study. Please contact the author for data requests.

\section{Author's contributions}

The author read and approved the final manuscript.

\section{Ethics approval and consent to participate}

All procedures performed in this study involving human participants were in accordance with the ethical standards of the Egyptian National Research Committee. The local ethical committee of the Alexandria Faculty of Medicine approved this study with approval reference number of 0303821 dated 18 January 2018. Informed consent for surgery was obtained from all individual participants included in the study

\section{Consent for publication}

Consent for publication was not required as details, images, or videos relating to individual participants were not used.

\section{Competing interests}

The author declares that he has no competing interests.

\section{Publisher's Note}

Springer Nature remains neutral with regard to jurisdictional claims in published maps and institutional affiliations.

Received: 20 December 2017 Accepted: 27 March 2018

Published online: 02 May 2018

\section{References}

1. Cohen ZR, Fourney DR, Marco RA, Rhines LD, Gokaslan ZL. Total cervical spondylectomy for primary osteogenic sarcoma: case report and description of operative technique. J Neurosurg. 2002;97:386-92.

2. Yonenobu K. Cervical radiculopathy and myelopathy: when and what can surgery contribute to treatment? Eur Spine J. 2000;9:1-7.

3. Baron EM, Young WF. Cervical spondylotic myelopath: a brief review of its pathophysiology, clinical course and diagnosis. Neurosurgery. 2007; 60:S35-41.

4. Chau AM, Xu LL, Wong JH, Mobbs RJ. Current status of bone graft options for anterior interbody fusion of the cervical and lumbar spine. Neurosurg Rev. 2014:37:23-37.

5. Liao JC, Niu CC, Chen WJ, Chen LH. Polyetheretherketone (PEEK) cage filled with cancellous allograft in anterior cervical discectomy and fusion. Int Orthop. 2008;32:643-8.

6. Chau AM, Mobbs RJ. Bone graft substitutes in anterior cervical discectomy and fusion. Eur Spine J. 2009;18:449-64.
7. Miller LE, Block JE. Safety and effectiveness of bone allografts in anterior cervical discectomy and fusion surgery. Spine (Phila Pa 1976). 2011;36:2045-50.

8. Chen ZH, Liu B, Dong JW, et al. Comparison of anterior corpectomy and fusion versus laminoplasty for the treatment of cervical ossification of posterior longitudinal ligament: a meta-analysis. Neurosurg Foxus. 2016;40:E8.

9. Andaluz N, Zuccarello M, Kuntz C. Long-term follow-up of cervical radiographic sagittal spinal alignment after 1-and 2-level cervical corpectomy for the treatment of spondylosis of the subaxial cervical spine causing radiculomyelopathy or myelopathy: a retrospective study clinical article. J Neurosurg Spine. 2012;16:2-7.

10. Vernon $\mathrm{H}$, Mior $\mathrm{S}$. The neck disability index: a study of reliability and validity. J Manip Physiol Ther. 1991;14:409-15.

11. Yan N, Yu S, Hou T, Gu G, Zhang H, Zhao S, et al. Cervical spondylotic myelopathy caused by single level vertebral spontaneous fusion. PLoS One. 2014;9(11):e112423.

12. Liu J, Chen X, Liu Z, Long X, Huang S, Shu Y. Anterior cervical discectomy and fusion versus corpectomy and fusion in treating two-level adjacent cervical spondylotic myelopathy: a minimum 5-year follow-up study. Arch Orthop Traum. 2015;135:149-53.

13. Wu JX, Luo D, Ye XJ, et al. Anatomy-related risk factors for the subsidence of titanium mesh cage in cervical reconstruction after one-level corpectomy. Int J Clin Exp Med. 2015;8:7405-11.

14. Heyde CE, Bohem H, El Saghir $H$, et al. Surgical treatment of spondylodiscitis in the cervical spine: a minimum 2-year follow-up. Eur Spine J. 2006;15:1380-7.

15. Shousha M, Heyde C, Boehm H. Cervical spondylodiscitis: change in clinical picture and operative management during the last two decades. A series of 50 patients and review of literature. Eur Spine J. 2015;24:571-6.

16. Wang CS, Chang JH, Chang TS, Chen HY, Cheng CW. Loading effects of anterior cervical spine fusion on adjacent segments. Kaohsiung J Med Sci. 2012:28(11):586-94.

17. Luo J, Cao K, Huang S, et al. Comparison of anterior versus posterior approach for the treatment of multilevel cervical spondylotic myelopathy. Eur Spine J. 2015;24(8):1621-30.

18. Kato S, Fehlings M. Degenerative cervical myelopathy. Curr Rev Musculoskelet Med. 2016;9(3):263-71.

\section{Submit your manuscript to a SpringerOpen ${ }^{\circ}$ journal and benefit from:}

- Convenient online submission

Rigorous peer review

- Open access: articles freely available online

- High visibility within the field

- Retaining the copyright to your article

Submit your next manuscript at $\boldsymbol{\nabla}$ springeropen.com 